Artigo recebido em

22/03/2014

Aprovado em

10/05/2014

CARLOS A.V. CASTILHO

EGC/UFSC castilho.pos@ gmail.com

Doutorando e Mestre em

Mídias do Conhecimento no EGC/UFSC. Jornalista,

membro da direção do

Observatório da Imprensa.

Áreas de pesquisa: A

Curadoria de Notícias como Fator de Produção

de Conhecimento; e

Comunicação Comunitária pela Internet.

CHRISTIANNE

C. S. ÃREINISCH

COELHO

EGC/UFSC christianne. ccsrc@gmail.com Doutora e Mestre em Engenharia da Produção (PPGEP/

UFSC). Professora

Colaboradora do Programa de Pós Graduação em

Engenharia e Gestão do Conhecimento (PPGEGC/

UFSC) e estudante no curso de Museologia da UFSC. Área de pesquisa: Sustentabilidade Ambiental e Teoria da Complexidade.

\section{Curadoria de notícias e jornalismo na produção de conhecimento}

\author{
Carlos A. V. Castilho e Christianne C. S. Reinish Coelho
}

\section{Resumo}

$\mathrm{O}$ artigo pretende abrir um debate sobre o papel que a curadoria de notícias tem na produção de conhecimento dentro do campo da comunicação jornalística. A curadoria de notícias é uma área nova dentro da pesquisa acadêmica e no exercício do jornalismo, o que torna a troca de experiências e percepções essencial para o desenvolvimento de uma base teórica.

Palavras-chave

Notícia, curadoria, conhecimento, capital social.

\begin{abstract}
This article looks forward the opening of a debate about the role of news curation as a knowledge production tool in journalism. News curation is a brand new area among academic researchers and professional journalists, making the exchange of experiences and perceptions a key issue for the development of its theoretical principles.
\end{abstract}

Keywords

News, curation, knowledge, social capital.
Estudos em Jornalismo e Mídia

Vol. $11 \mathrm{~N}^{\circ} 1$

Janeiro a Junho de 2014

ISSNe 1984-6924 


\section{Contextualização da curadoria no jornalismo}

super-oferta
gerada pela multiplicação
de canais digitais de
comunicação na internet criou o ambiente propício para que a curadoria surgisse como um instrumento capaz de recomendar as informações mais adequadas às necessidades e desejos de leitores, ouvintes, telespectadores e internautas. Trata-se de uma área de pesquisa cujos desdobramentos sinalizam importantes mudanças tanto na teoria como na prática do jornalismo. A mais relevante de todas as novas perspectivas é a recuperação da função do jornalismo como ferramenta para a produção de conhecimento.

Este artigo é uma contribuição ao início de um debate sobre curadoria de notícias no exercício do jornalismo. Embora a
1- Detalhes sobre o histórico da curadoria podem ser encontrados no capitulo Anotações para a Compreensão da Atividade do Curador de Informação Digital, de autoria de Daniela Ramos, no livro eletrônico $A$ Curadoria Digital e o Campo da Comunicação. Ver Referências Bibliográficas 2- Ver referências bibliográficas.

3- Slashdot: $\underline{\text { http:// }}$ slashdot.org 4-Detalhes em: http://curationnation. org

5-O gráfico pode ser acessado em: http://www.google. com/trends/explore\#q= content $\% 20$ curation, acessado em 21/3/2014 consequência do fato da curadoria de quais é ou pode ser utilizada.

A controvérsia conceitual é uma notícias ser um tema muito recente no campo da comunicação e do jornalismo. As primeiras publicações sobre curadoria de notícias surgiram em universidades norte-americanas por volta de 2011 e aqui no Brasil, os primeiros trabalhos foram desenvolvidos pela professora Elizabeth Saad Correia, que em 2013 coordenou a edição do livro eletrônico A Curadoria Digital e o Campo da Comunicação ${ }^{2}$.

O impulso inicial para o crescimento da importância da curadoria de notícias foi dado pelas ciências da computação e pelo marketing corporativo. Em 1997 surgiu a revista eletrônica Slashdot ${ }^{3}$ que formou uma comunidade de programadores e pesquisadores para selecionar e contextualizar informações em meio à avalancha informativa. Em 2011, Steven Rosenbaum publicou o livro Curation Nation ${ }^{4}$ que sintetizou a expectativa dos especialistas em marketing corporativo de usar a curadoria para filtrar e agregar valor a informações distribuídas a clientes.

O segmento empresarial foi o primeiro a identificar a necessidade de filtrar, selecionar, agregar valor e difundir informações capazes de reduzir a margem de erro em processos produtivos, gerada pelo excesso de dados não contextualizados.

O serviço Google Trends ${ }^{5}$ registrou o forte crescimento das buscas sobre o tema content curation (curadoria de conteúdos informativos) a partir do final de 2010. O gráfico desenvolvido pelo Google Trends mostra um aumento vertiginoso no interesse pelo tema entre os anos de 2011 e 2013, período no qual predominou a preocupação com as aplicações da curadoria no marketing.

O caráter exploratório e empírico das 
primeiras experiências de curadoria de notícias criou condições para o surgimento de uma considerável diversidade conceitual que pode ser observada nas entrevistas realizadas com jornalistas e professores de jornalismo para identificar percepções sobre o tema ${ }^{6}$.

Na literatura acadêmica, Ramos (2012) classifica o curador como um mediador, enquanto Liu prefere definir os curadores como "guias de nossa história" (LIU, 2010, p. 18). Scoble compara a curadoria de notícias a uma "alquimia informativa", mediante a recombinação de "átomos informativos formadores de info-

\section{A exxpressão curadoria} aparece cadla vez mais em publicações acadêmicas e não acadêmicas focadas na comunicação e no jornalismo

células" (SCOBLE, 2010). Kastelle acha que o fator econômico é preponderante na curadoria porque ela agrega valor à notícia (KASTELLE, 2010).

Os depoimentos de jornalistas mostraram que a maioria dos entrevistados identifica curadoria com edição de notícias. A percepção é de que ambas as expressões são sinônimas, pois a edição jornalística usa as mesmas ferramentas da curadoria ao selecionar, agregar valor (editar) e difundir (publicar) notícias visando oferecer a leitores, ouvintes, telespectadores e internautas um cardápio informativo voltado para o desenvolvimento da cidadania.

Vista nesta perspectiva, a divergência sobre o uso da expressão curadoria no ambiente jornalístico não faria sentido porque os enfoques seriam coincidentes. Mas a análise mais detalhada da questão mostra diferenças relevantes, determinadas principalmente pelo contexto em que estão situadas, tanto a edição como a curadoria.

\section{Diferenças entre notícia,}

\section{dado e informação}

A inserção da curadoria no campo jornalístico é parte do surgimento e consolidação do ambiente digital na comunicação humana. A compreensão deste processo implica referenciar a prática do jornalismo a questões como a complexidade e a diferenciação entre dado, informação e conhecimento.

Dado é um número, fato, evento ou objeto captado pelos sentidos humanos antes de ser inserido no contexto do indivíduo receptor ${ }^{7}$. Informação é um dado que assumiu um significado específico no contexto do receptor mediante a identificação de fatores como causas, consequências, beneficiados ou prejudicados.

O conhecimento resulta da recombinação de informações gerando um posicionamento ou tomada de decisão. Uma notícia é um dado cuja especificidade está em sua originalidade ou ineditismo para o indivíduo receptor.

O que diferencia um dado e/ou uma notícia de uma informação é a incorporação de significado. Uma notícia é recebida como um dado porque é
6- Foram realizadas 10 entrevistas em duas séries. A primeira série de perguntas abertas procurou identificar percepções imediatas sobre curadoria de noticias. As respostas foram codificadas e categorizadas seguindo as normas da Teoria Fundamentada em Dados (Grounded Theory). A segunda série de entrevistas procurou explorar reações aos resultados da categorização.

7- As definições, com exceção do conceito de noticia, foram baseadas na apresentação do professor Roberto Carlos Pacheco e disponível em http://www.slideshare.net/rpachecol engenharia-do-conhecimento-e-inteligncia-artificial-aula-13 O conceito de noticia como dado inédito é responsabilidade do autor deste artigo. 
8- Detalhes em http:// www.businessinsider. com/75-billion-devices-will-be-connected-to-the-internet-by-2020-2013-10 Acessado em 18/03/2014

9- O conceito de notícia usado neste artigo foi desenvolvido a partir das definições de Adelmo Genro Filho (singularidade) $e$ de Sperber e Wilson (dado, fato ou evento relevante). Notícia é um dado, fato ou evento caracterizado por sua singularidade, ineditismo, relevância, pertinência e confiabilidade envolvendo, no mínimo: dois protagonistas (um emissor e um receptor) e um canal de comunicação. 10- Por usabilidade entendemos $o$ conceito ampliado de Jakob Nielesen sobre a facilidade com que as pessoas absorvem informações publicadas em algum veículo de comunicação. O conceito de usabilidade ganhou relevância na internet mas é aplicável a outras formas de comunicação. http:// www.nngroup.com/ articles/usability101-introduction-to-usability $\Lambda$ ) acessado em 13/12/2013. captada pelos sentidos humanos, antes de ser codificada e categorizada pelo indivíduo receptor. $\mathrm{O}$ dado 75 bilhões de processadores em $2020^{8}$ pode ser uma notícia para quem ignora o seu significado e relevância, mas passa a ser uma informação depois que o indivíduo descobre que o número se refere à previsão feita pela empresa Cisco sobre a quantidade de equipamentos dotados de microprocessadores conectados a internet no final da segunda década do século XXI.

E se transforma em conhecimento quando o mesmo receptor, depois de interagir com outros indivíduos e pesquisar em publicações ou bancos de dados, assume que sua vida vai sofrer grandes mudanças com a interconexão via redes virtuais entre pessoas e equipamentos como parte do fenômeno conhecido como "internet das coisas".

A notícia pode ser considerada uma componente chave na produção de conhecimento porque ela é uma das principais causas do que Sperber e Wilson (1996) classificaram como "desequilíbrio cognitivo". Uma notícia, dado inédito, introduz um dado novo no ambiente cognitivo de um indivíduo reforçando, modificando ou anulando conhecimentos acumulados nas memórias de curto prazo.

Esta alteração provoca reações como insegurança, medo, incerteza ou curiosidade que levam o indivíduo a refletir individual ou coletivamente na busca de um novo equilíbrio cognitivo.

O detalhamento da relação entre notícia, dado e informação pode ser feito por meio da análise de três elementos: Processamento da matéria prima, formatação do produto final e ambiente tecnológico.

\section{Processamento da matéria prima}

A matéria prima do jornalismo praticado em empresas de comunicação é formada por dados inéditos que são selecionados tendo em vista a comercialização na forma de notícia, como um produto com valor de troca9 A edição de uma notícia leva em conta a atualidade, relevância, pertinência, confiabilidade e usabilidade ${ }^{10}$ da matéria prima inicial.

A curadoria também trabalha com a mesma matéria prima, mas a processa de uma forma diferente da edição. Em primeiro lugar, a atualidade não é um fator tão importante na seleção do material como no jornalismo. $\mathrm{Na}$ curadoria, predomina o interesse e a necessidade do usuário personalizado, enquanto no jornalismo industrial ocorre a produção massificada de notícias.

A seleção de notícias no jornalismo convencional, praticado na maioria das grandes empresas contemporâneas de comunicação, baseia-se no processo conhecido pelo jargão inglês gatekeeper, o porteiro. Um profissional, ou uma equipe de profissionais, é responsável pela seleção das informações recolhidas e que serão submetidas ao processo de edição e publicação. É um processo hierárquico, centralizado e estruturalmente unidirecional enquanto na curadoria o foco é a interatividade descentralizada e horizontal.

Já a curadoria seleciona notícias a partir de uma preocupação com o gatewatching, jargão inglês para observação de fontes. Enquanto o pauteiro (porteiro/ gatekeeper) procura afunilar a seleção de notícias devido às limitações de espaço, 
ou tempo, na publicação, a preocupação do curador é ampliar a amostra para seleção para oferecer ao seu público a maior diversidade possível de opções informativas.

\section{Formatação do produto final}

A notícia, como produto básico de um veículo de comunicação jornalística, está formatada segundo as necessidades de um processo industrial previsto nos manuais de redação que orientam o trabalho dos profissionais atuando em veículos impressos, audiovisuais e multimídias. Trata-se de um processo altamente normatizado, preocupado com a isenção e voltado para o desenvolvimento de um produto comercializável, numa troca de atenção do leitor por espaços publicitários pagos.

O interesse do público por notícias inéditas, relevantes, pertinentes $\mathrm{e}$ confiáveis funciona como "isca" para deslocar a atenção para anúncios comerciais publicados no mesmo veículo de comunicação. A isenção, imparcialidade e objetividade são tratadas como elementos necessários para transmitir a percepção de confiabilidade, que é um item chave na aferição do valor de troca de uma notícia publicada em um grande jornal, por exemplo.

A curadoria de noticias segue uma formatação distinta cuja caracterização está baseada na observação de fontes de informação, em sua maioria situadas em ambiente digital, como é o caso do projeto $S \operatorname{coop} p^{11}$, uma rede de sites de curadoria. A curadoria de notícias praticada em ambiente digital online assume, na maioria dos casos, a forma de um blog pessoal ou coletivo de blogs onde o curador faz recomendações de softwares, pesquisas, artigos teóricos e iniciativas de outros curadores.

A observação de blogs de curadoria como o Content Curation World ${ }^{12}$ identificou outro grande diferencial que é a interatividade entre curador e os membros de sua rede de usuários. Foram observadas 17.907 interações no blog Content Curation World num período de seis meses.

As interações tem como ponto em comum a preocupação com o valor de uso das notícias recomendadas, o que gera a necessidade de um maior conhecimento das características, necessidades e desejos dos participantes da troca de sugestões e observações. A personalização dos conteúdos recomendados no processo de curadoria de notícias é muito maior do que a de uma notícia publicada em veículos convencionais de comunicação jornalística.

\section{Ambiente tecnológico}

A notícia jornalística está vinculada a um ambiente de escassez informativa e restrições espaciais determinadas essencialmente pelas limitações tecnológicas existentes antes do surgimento da era digital e das novas TICs (Tecnologias de Informação e Comunicação). A escassez era uma consequência da inexistência de sistemas mais rápidos e diversificados de transmissão de dados, informações e conhecimentos. A natureza mecânica e material dos processos de produção de jornais, revistas, noticiários de radio e televisão impõem a necessidade de notícias curtas e objetivas, onde a
10- A rede Scoop (www.scoop.it) é formada por cerca de mil blogs de curadoria sobre diversos temas. Predominam os blogs sobre notícias tecnológicas e sobre marketing.

11- Durante seis meses foi observada a prática do curador e usuários do blog Content Curation World (www.curation.masternewmedia.org), produzido por um dos pioneiros da curadoria de informações, Robin Good. Os dados e a analise do monitoramento fazem parte de um projeto de tese a ser defendido, em 2014, no Departamento de Engenharia e Gestão do Conhecimento (EGC) da 
12- Information brokers ou agentes de informações são profissionais especializados em buscas por encomenda e que pesquisam dados ou fatos conforme instruções de clientes, em geral corporações industriais, agrícolas ou comerciais.

13- Ver em https:// news.google.com/ 14- Ver em http:// narrativescience. com/

15- O texto

da pesquisa está disponível em. https:// reutersinstitute. politics.ox.ac.uk/ fileadmin/documents/ Publications/

fellows

papers/2012-2013/

Newsroom

Curators

Independent

Storytellers -

content curation as a new form of journalism.pdf 16-Detalhes em http://storify.com 1 17-Detalhes em http://storyful.com / 18- Ver em http:// www.livescribe.com/ 19- Citação extraí- contextualização era reduzida ao mínimo possível.

Mas o ambiente tecnológico onde está inserida a produção de notícias jornalísticas começou a mudar a partir do final do século XX com o avanço dos processos digitais, da expansão global da rede mundial de computadores (internet) e a crise no modelo de negócios baseado no valor de troca da notícia.

A curadoria de notícias já existia antes do início da era digital quando era desenvolvida por um pequeno número de profissionais altamente especializadas mais conhecidos pelo nome de information brokers ${ }^{13}$. A função ganhou uma relevância muito maior dentro do contexto tecnológico criado pelas TICs, como uma resposta aos efeitos desorientadores da avalancha informativa deflagrada pela combinação da computação e da internet. A super oferta de notícias e informações tornou essencial a seleção, filtragem e contextualização dos conteúdos publicados na internet para que indivíduos e organizações possam tomar decisões adequadas às suas necessidades e desejos.

A curadoria de notícias em ambiente digital ganhou um forte impulso com o desenvolvimento dos algoritmos de seleção, filtragem, agregação de valor e disseminação de dados. A produção automática de notícias customizadas conquistou espaços com o êxito de programas como o Google News ${ }^{14}$ e Narrative Science ${ }^{15}$.

O primeiro tornou-se o paradigma dos serviços de produção e distribuição de notícias de atualidade enquanto o Narrative Science utiliza algoritmos sofisticados para selecionar, editar e redigir notícias utilizadas especialmente por publicações voltadas para o mercado corporativo.

Uma pesquisa desenvolvida por Federico Guerrini para o Instituto Reuters mostra que todas as grandes empresas jornalísticas da Europa, America do Norte e Japão utilizam softwares como Storify ${ }^{17}$, Storiful $^{18}$ e ScribeLive ${ }^{19}$ como ferramenta de curadoria de notícias. Estes programas promovem a busca de dados na Web, os organizam em textos, imagens ou sons, e os distribuem para clientes.

O projeto Scoop It combina o uso de algoritmos para acelerar e facilitar a interação entre curadores e entre estes e seus seguidores. Guillaume Decugis, o engenheiro e empreendedor que criou o Scoop It em 2011 afirmou: "Nós criamos o Scoop It porque nós acreditamos que apenas os algoritmos não são suficientes para organizar os conteúdos da Web de forma inteligente e significativa" 20 .

\section{Avalancha informativa e a curadoria de notícias}

A digitalização combinada com a expansão vertiginosa da rede mundial de computadores (internet) e do conjunto de interfaces gráficas para representação visual e auditiva de dados digitalizados (Web) tornou possível a publicação de notícias por pessoas sem formação técnica em jornalismo. $\mathrm{O}$ fim da exclusividade dos jornalistas profissionais e das empresas jornalísticas na produção e distribuição de notícias é um dos fatores que contribuíram para o avassalador crescimento da oferta informativa na internet.

Dados divulgados pela empresa Cisco, em fevereiro de 2014, estimam em 1,5 exabyte o volume de informações 
digitalizadas que circulam por mês em todo mundo pelo sistema de comunicação via celulares nos formatos voz e dados. Por ano seriam 18 exabytes ou 18 bilhões de gigabytes, volume equivalente ao total de dados digitalizados na internet no ano 2000. Ainda segundo a Cisco, o fluxo de dados e informações no sistema de comunicação móvel cresce $81 \%$ ao ano em todo o planeta ${ }^{21}$.

A avalancha informativa não é um evento passageiro na transição para um modelocomunicacionalmajoritariamente digital $^{22}$. Ela é um fenômeno estrutural na medida em que a telemática ${ }^{23}$ e o uso processadores microeletrônicos se tornaram o elemento central no novo modelo de produção econômica global baseada na digitalização. A economia mundial contemporânea só é sustentável pelo uso intensivo de processos digitais o que gera um fluxo exponencial de novos dados, fatos e eventos. (BENKLER, 2006).

A oferta de mais notícias, informações e conhecimentos está umbilicalmente vinculada aos processos geradores de inovações em todos os setores da atividade humana, processos estes que alimentam o desenvolvimento econômico em escala mundial (BENKLER, 2006).

\section{Segmentação informativa}

A superoferta de informação trouxe como corolário a segmentação informativa, já que o excesso de insumos noticiosos $\mathrm{e}$ as limitações técnicas temporárias dos algoritmos curadores provocaram o surgimento de nichos informativos para atender suas necessidades e desejos dos consumidores de informações, conforme constatou
Chris Anderson, o autor do livro Cauda Longa ${ }^{24}$.

A multiplicação de sites autônomos de produção de informações segmentadas aumentou a diversidade informativa na internet e criou as condições necessárias para o crescimento do número de projetos de curadoria de notícias. Estas iniciativas, segundo Bruns (2005) complementaram o trabalho dos veículos jornalísticos convencionais que não tem condições materiais de selecionar e editar toda a vasta gama de conteúdos publicados na internet.

A verificação da exatidão e a certificação de credibilidade são dois principais elementos que diferenciam uma notícia produzida por jornalistas da divulgada por praticantes de atos jornalísticos. Os profissionais do jornalismo são regidos por normas e códigos de ética que estabelecem regras a serem seguidas em matéria de qualidade da informação publicada. Já os autônomos não estão submetidos aos mesmos padrões o que abre espaço para os curadores de notícias funcionaram como certificadores de credibilidade.

Para Villi (2012), a curadoria de notícias não substitui o sistema jornalístico de processamento de fatos, dados e eventos com características de noticiabilidade (ineditismo, relevância, pertinência, exatidão e credibilidade). Para o autor, a curadoria de notícias e a edição jornalística são atividades complementares que usam uma mesma matéria prima, o dado (números, fatos, eventos e objetos) e visam um mesmo público, indivíduos consumidores de informações.

Ambas divergem nos métodos de seleção, filtragem de notícias que ao serem
20-Detalhes em Mundo consome 1,5 exabyte por mês em dados móveis . Jornal O Globo , edição de 11/2/2014

21- Usamos a expressão majoritariamente porque todos os indicios históricos apontam no sentido de que a digitalização não eliminará os processos analógicos de comunicação. A tendência atual é a predominância do formato digital na publicação de textos, áudios e imagens, mas o formato impresso bem como o uso de fotografias e filmes animados com base em celuloide continuará a existir em nichos especializados de produção artística.

22- Telemática é o conjunto de sistemas de transmissão eletrônica de dados digitalizados por meio de redes de computadores.

23- ANDERSON,

Chris. A Cauda

Longa, The LongTail, do Mercado de Massa ao Mercado de Nicho. Campus/ Elsevier, São Paulo. Versão eletrônica do livro disponível online no site do Projeto de Democratização da Leitura - www. portaldetonando. 
contextualizadas assumem a forma de informação que é disseminada e serve de insumo para a produção de conhecimento pelo público receptor. Villi (2012) destaca também que os curadores autônomos de notícias tendem a se agrupar em comunidades de curadoria, configurando o que ele definiu como curadoria social. A rede Scoop It é um exemplo concreto desta tendência.

\section{Curadoria e conhecimento}

Boisot e Cox (1999, p. 535) afirmam que o processo de formação de um novo conhecimento se inicia quando a instabilidade provocada pela alteração do ambiente cognitivo gera uma recombinação envolvendo informações armazenadas na memória do indivíduo e os dados captados pelos sentidos.

Como uma notícia jornalística é um dado cuja especificidade para um indivíduo é o seu ineditismo, ela funciona como disparador de processos de recombinação caracterizados pela avaliação de relevância, pertinência e confiabilidade. Boisot identificou nos dados inéditos (notícias jornalísticas) um maior potencial de aceleração da recombinação porque eles geram mais incertezas pelo fato de serem desconhecidospeloindivíduo. Estabeleceu também que a avaliação da relevância, pertinência e confiabilidade ocorre por meio da codificação e categorização dos elementos que compõem a notícia, num processo em que o indivíduo recombina o que ele já conhece com o que ele está conhecendo a partir da absorção de um dado inédito.

\section{Considerações finais}

A relevância assumida pela notícia como fator deflagrador da produção de conhecimento em indivíduos está associada ao papel que a curadoria exerce na seleção de material integrante da avalancha informativa gerada pelas TICs.

Notícia, jornalismo, curadoria e conhecimento formam um conjunto de fatores associados por uma relação dinâmica e interativa, onde cada um deles influi e é influenciado pelos demais. A curadoria filtra a massa de notícias inserida na avalancha e agrega valor ao material selecionado, permitindo que um indivíduo disponha de insumos geradores de um processo de recombinação de dados e informações capazes de produzir conhecimentos mais adequados aos desejos e necessidades deste mesmo indivíduo. A curadoria amplia assim o valor de uso da notícia e confere ao jornalismo uma função na geração de conhecimento socialmente relevante que havia sido negligenciada quando as indústrias da comunicação jornalística privilegiaram o valor de troca do produto noticioso. A consolidação da curadoria de notícias como processo integrado ao campo do jornalismo e vinculado à produção de conhecimento ainda depende de um maior desenvolvimento da sistematização das experiências realizadas até agora e de uma base teórica mais consistente. $\mathrm{O}$ debate e a consequente recombinação de ideias e percepções parece ser a estratégia mais adequada para atingir estes dois objetivos. 


\section{Referências bibliográficas}

ANDERSON, Chris. A Cauda Longa: do Mercado de Massa ao Mercado de Nicho. São Paulo: Campus/Elsevier, 2006. Versão disponível online no site do Projeto de Democratização da Leitura em: www.portaldetonando.com.br

BENKLER, Yochai. The Wealth of Networks. New Heaven, Connecticut: Yale University Press, 2006.

BOISOT, Max e COX, Benita. The I-Space: a framework for analyzing the evolution of social computing. Technovation, 19, 1999. pp. 525-536.

BRUNS, Axel. Gatewatching. Nova Iorque: Peter Lang Publishing, 2005.

KASTELLE, Tim. Five Forms of Filtering. Innovation. Leadership Network. Abril de 2010. Disponível em: http://timkastelle.org/blog/2010/04/five-forms-of-filtering/ Acessado em 17/3/2014

\section{LIU, Sophia. Trends in Distributed Curatorial Technology to Manage Data}

Deluge in a Networked World. Emerging Information Technologies. UpGrade, v. XI, n. 4 , 2010 Disponível em http://www.cepis.org/upgrade/media/liu.IV.20101.pdf, acessado em 19/3/2014.

PACHECO, Roberto C. Introdução à Engenheria do conhecimento - Aula 4. Disponível em http://www.slideshare.net/rpacheco/engenharia-do-conhecimentoe-inteligncia-artificial-aula-13 Acessado em 19/3/2014

RAMOS, Daniela. Anotações para a compreensão da atividade do "Curador de Informação Digital”. In: Curadoria Digital e o Campo da Comunicação. São Paulo: ECA/USP, 2012. Disponível em: http://issuu.com/grupo-ecausp.com/docs/ebook curadoria digital usp/57\#download Acessado em 12/03/2014

ROSENBAUM, Steven. Curation Nation: How to Win in a World Where Consumers are Creators. Nova Iorque: McGraw Hill, 2011.

SAAD CORREIA, Elizabeth. A Curadoria Digital e o Campo da Comunicação. São Paulo: ECA-USP, 2012. Disponível em: http://issuu.com/grupo-ecausp.com/docs/ ebook curadoria digital usp\#download Acessado em 11/03/2014

SCOBLE, Robert . The Seven Needs of Real Time Curators. Scobleizer, 2010, Disponivel em: http://scobleizer.com/2010/03/27/the-seven-needs-of-real-timecurators/ acessado em 19/3/2014

SPERBER, Dan; WILSON, Deirdre. Relevance: Communication and Cognition. 2. ed. Nova Jersey: Wiley-Blackwell, 1996.

VILLI, Miko. Social Curation in Audience Communities in the networked media ecosystem. Participations Journal of Audience \& Reception Studies. v. 9, n. 2, Novembro 2012. pp. 614-616. 